\title{
Origin of the Helminth Community of an Exotic Invasive Lizard, the Brown Anole, Anolis sagrei (Squamata: Polychrotidae), in Southwestern Taiwan ${ }^{1}$
}

\author{
Gerrut Norval, ${ }^{2}$ Charles R. Bursey, ${ }^{3}$ Stephen R. Goldberg, ${ }^{4,6}$ Jean-fay Mao, ${ }^{5}$ and Kerry Slater ${ }^{2}$
}

\begin{abstract}
Composition of the helminth community of the brown anole, Anolis sagrei, an exotic invasive species in Taiwan, was studied to identify the emigration point of this lizard. A total of 5,757 helminths was found, of which 5,734 (99.6\%) were the nematode Cyrtosomum penneri. Also found were the digenean Mesocoelium monas $(21,0.4 \%)$ and one each of the nematodes Parapharyngodon sp. (female) and Acuariidae gen. sp. (larva). Cyrtosomum penneri has previously been reported in A. sagrei in Florida, supporting the contention that the Taiwan population of $A$. sagrei originated from Florida. This report provides a basis upon which future $A$. sagrei parasite studies in Taiwan can be based, and a helminth list for $A$. sagrei is included for future reference.
\end{abstract}

The brown anole, Anolis sagrei Duméril and Bibron, 1837 , is native to Cuba, the Bahamas, and adjacent islands (Henderson and Powell 2009). It is a widespread and successful colonizer, and Kraus (2009) published a list of invaded sites, suggesting Hawai'i and Taiwan as more recent sites of colonization. The Hawaiian $\left(\mathrm{O}^{\prime} \mathrm{ahu}\right)$ population was first noticed in 1980 (McKeown 1996) and is most likely of Florida or Caribbean origin (Goldberg and Bursey 2000). The Taiwan population was first noted in 2000 and because the highest concentration occurred in the immediate vicinity of a plant nursery (Norval et al. 2002),

\footnotetext{
${ }^{1}$ Manuscript accepted 21 September 2010.

${ }^{2}$ Applied Behavioural Ecology and Ecosystem Research Unit, Department of Environmental Sciences, University of South Africa (UNISA), Private Bag X6, Florida, 1710, Republic of South Africa.

${ }^{3}$ Department of Biology, Pennsylvania State University, Shenango Campus, Sharon, Pennsylvania 16146.

${ }^{4}$ Department of Biology, Whittier College, Whittier, California 90608.

${ }^{5}$ Department of Natural Resources, National Ilan University, No. 1, Shen-Lung Road Sec. 1, Ilan 260, Taiwan, Republic of China.

${ }^{6}$ Corresponding author (e-mail: sgoldberg@whittier .edu).
}

Pacific Science (2011), vol. 65, no. 3:383-390

doi: $10.2984 / 65.3 .383$

(C) 2011 by University of Hawai'i Press

All rights reserved it is likely that these lizards were introduced with nursery products. The effects of parasite introductions by invasive reptiles merit investigation as part of the ecological and socioeconomic impact of naturalized animals (Lever 2003). Introduced brown anoles are considered to have originated from Florida (Kolbe et al. 2004) and have transported helminth parasites of Florida/Caribbean distributions to Hawai'i (Goldberg and Bursey 2000). Identification of the helminths present in introduced reptiles is important in tracing emigration pathways. The purpose of the study reported here was to examine the helminth population harbored by $A$. sagrei in Taiwan to identify their emigration site and to provide a basis upon which future $A$. sagrei parasite studies in Taiwan can be based.

\section{MATERIALS AND METHODS}

Between 20 September 2007 and 19 September 2008, 347 brown anoles (175 male, snoutvent length $[\mathrm{SVL}]=24-60 \mathrm{~mm} ; 172$ female, SVL $=22-47 \mathrm{~mm}$ ) were collected monthly by hand at night in agricultural fields, a cemetery, and along roads in Santzepu, Sheishan District, Chiayi County, Taiwan (23 25' 51" N, $120^{\circ} 28^{\prime} 30^{\prime \prime}$ E). Due to typhoon Kalmaegi, no sample was obtained for July 2008. At the point of capture each specimen was allocated a field number. The following morning, each lizard was measured to the nearest millimeter 
TABLE 1

Number, Prevalences (\%), Mean Intensity \pm 1 SD, Range, and Abundance for Helminths of Anolis sagrei from Taiwan

\begin{tabular}{lrcccr}
\hline \hline Helminth & $n$ & Prevalence & Mean Intensity & Range & Abundance \\
\hline $\begin{array}{l}\text { Digenea } \\
\quad \text { Mesocoelium monas }\end{array}$ & 21 & 3.7 & $1.6 \pm 1.2$ & $1-5$ & 0.061 \\
Nematoda & & & & & $1-265$ \\
$\quad$ Cyrtosomum penneri & 5,734 & 37.7 & $43.7 \pm 50.3$ & - & 16.524 \\
$\quad \begin{array}{l}\text { Parapharyngodon sp. } \\
\text { Acuariid larva }\end{array}$ & 1 & 0.3 & 1 & -003 \\
\hline
\end{tabular}

with a transparent plastic ruler, then killed with ether, and fixed by injecting $10 \%$ formalin into the body cavity. After a 2-day fixation period, each specimen was placed individually in a sealed plastic bag filled with $75 \%$ alcohol. All specimens were shipped to Whittier College, Whittier, California, where the body cavity of each lizard was opened by a longitudinal incision from throat to vent and the gastrointestinal tract was removed by cutting across the esophagus and rectum. The esophagus, stomach, and small and large intestines were slit longitudinally and separately searched for helminths under a dissecting microscope. The wall of the digestive tract was also examined for cysts containing larval helminths. For study, helminths were cleared in a drop of undiluted glycerol on a glass slide. Nematodes were identified from these temporary preparations; digeneans were regressively stained in hematoxylin, cleared in xylene, and mounted in Canada balsam. Identifications are based upon the reference keys of Anderson et al. (1974) and Prudhoe and Bray (1982). Population terminology is according to Bush et al. (1997). Statistical analysis followed the methods outlined by Brower et al. (1998). The anoles were deposited in the herpetology collection of the Natural History Museum of Los Angeles County (LACM), Los Angeles, California. Selected helminths were deposited in the United States Parasite Collection (USNPC), Beltsville, Maryland, as Mesocoelium monas (USNPC 101987, 101988), Cyrtosomum penneri (USNPC 101989), Parapharyngodon sp. (USNPC 101990), and Acuariidae gen. sp. (USNPC 101991).

\section{RESULTS}

One hundred and thirty seven (39\%) anoles harbored a total of 5,757 helminths. Four species of helminths were found: one digenean species, Mesocoelium monas (Rudolphi, 1819) Freitas, 1957 (small intestine); and three nematode species, Cyrtosomum penneri Gambino, 1957 (large and small intestines), an unidentified species of Parapharyngodon (large intestine), and a larva of an acuariid nematode (small intestine). The number, prevalence (number of infected host species as percentage), mean intensity (mean number of helminths per infected host), and abundance (total number of parasites in a host sample divided by total number of hosts in the sample) by helminth species are given in Table 1 . Other reported helminths from $A$. sagrei are listed in Table 2. Of the 5,757 helminths found in A. sagrei from Taiwan, 5,734 (99.6\%) were individuals assigned to $C$. penneri based on the spicule appearance. There was no significant difference in infection rate of male and female anoles by $C$. penneri $\left(\chi^{2}=3.18\right.$, $\mathrm{ddf}=1, P>.05)$; thus, no subsequent separation of data by host gender was made. The numbers of individuals of the other identified helminth species are too few for analysis by gender. For $C$. penneri, prevalence by month is given in Figure 1, and abundance (total number of parasite individuals/total number of hosts) by month is given in Figure 2. One hundred and thirty one $(96 \%$ of infected hosts) anoles were infected by $C$. penneri; 13 anoles $(9 \%)$ by $M$. monas, one anole $(<1 \%)$ by a Parapharyngodon sp., and one anole by an 
TABLE 2

Reported Helminths of Anolis sagrei

\begin{tabular}{|c|c|c|c|}
\hline Helminth & Locality & Prevalence & Reference \\
\hline \multicolumn{4}{|l|}{ Acanthocephala } \\
\hline \multirow[t]{2}{*}{ Acanthocephalus bufonis } & Hawai'i & $2 / 62$ & Goldberg and Bursey (2000) \\
\hline & Hawai'i & $8 / 281$ & Goldberg et al. (2002) \\
\hline Centrorbynchus sp. & Bahamas & $1 / 12$ & Goldberg et al. (1994) \\
\hline \multicolumn{4}{|l|}{ Eucestoda } \\
\hline Oochoristica sp. & Hawai'i & $8 / 281$ & Goldberg et al. (2002) \\
\hline \multicolumn{4}{|l|}{ Nematoda } \\
\hline Abbreviata sp. ${ }^{a}$ & Cuba & $12 / 138$ & Coy Otero and Barus (1979) \\
\hline Acuariidae $\mathrm{e}^{a}$ & Hawai'i & $66 / 281$ & Goldberg et al. (2002) \\
\hline Atractis opeatura & Cuba & $2 / 138$ & Coy Otero and Barus (1979) \\
\hline \multirow{2}{*}{ Atractis scelopori } & Hawai'i & $39 / 62$ & Goldberg and Bursey (2000) \\
\hline & Hawai'i & $189 / 281$ & Goldberg et al. (2002) \\
\hline Cyrtosomum penneri & Florida & $22 / 25$ & Goldberg et al. (1994) \\
\hline \multirow[t]{6}{*}{ Cyrtosomum scelopori } & Bahamas & $23 / 45$ & Goldberg et al. (1994) \\
\hline & Cuba & $4 / 21$ & Barus and Coy Otero (1969) \\
\hline & Cuba & $4 / 21$ & Coy Otero (1970) \\
\hline & Cuba & $4 / 19$ & Coy Otero and Barus (1973) \\
\hline & Cuba & $33 / 138$ & Coy Otero and Barus (1979) \\
\hline & Florida & $36 / 100$ & Price and Underwood (1984) \\
\hline \multirow[t]{2}{*}{ Oswaldocruzia lenteixeirai } & Bahamas & $3 / 45$ & Goldberg et al. (1994) \\
\hline & Cuba & $3 / 138$ & Coy Otero and Barus (1979) \\
\hline Ozolaimus monhystera & Cuba & $2 / 138$ & Coy Otero and Barus (1979) \\
\hline \multirow{4}{*}{ Parapharyngodon cubensis } & Bahamas & $1 / 45$ & Goldberg et al. (1994) \\
\hline & Cuba & $1 / 21$ & Barus and Coy Otero (1969) \\
\hline & Cuba & $1 / 21$ & Coy Otero $(1970)$ \\
\hline & Cuba & $2 / 138$ & Coy Otero and Barus (1979) \\
\hline \multirow[t]{6}{*}{ Physaloptera squamatae } & Bahamas & $20 / 45$ & Goldberg et al. (1994) \\
\hline & Cuba & $3 / 138$ & Coy Otero and Barus (1979) \\
\hline & Florida & $50 / 100$ & Price and Underwood (1984) \\
\hline & Florida & $15 / 25$ & Goldberg et al. (1994) \\
\hline & Hawai'i & $61 / 62$ & Goldberg and Bursey (2000) \\
\hline & Hawai'i & $165 / 281$ & Goldberg et al. (2002) \\
\hline Physalopteridae gen. sp. & Cuba & $1 / 138$ & Coy Otero and Barus (1979) \\
\hline \multirow[t]{2}{*}{ Physocephalus sp. ${ }^{.}$} & Hawai'i & $50 / 62$ & Goldberg and Bursey (2000) \\
\hline & Hawai'i & $145 / 281$ & Goldberg et al. (2002) \\
\hline \multirow{2}{*}{ Porrocaecum sp. ${ }^{a}$} & Bahamas & $1 / 45$ & Goldberg et al. (1994) \\
\hline & Cuba & $5 / 138$ & Coy Otero and Barus (1979) \\
\hline \multirow[t]{3}{*}{ Skrjabinoptera phrynosoma } & Cuba & $7 / 21$ & Barus and Coy Otero (1969) \\
\hline & Cuba & $7 / 21$ & Coy Otero $(1970)$ \\
\hline & Cuba & $55 / 138$ & Coy Otero and Barus (1979) \\
\hline Strongyloides sp. & Bahamas & $1 / 45$ & Goldberg et al. (1994) \\
\hline Trichospirura teixeirai & Cuba & $13 / 138$ & Coy Otero and Barus (1979) \\
\hline \multicolumn{4}{|l|}{ Pentastomida } \\
\hline Kiricephalus pattoni $i^{b}$ & Taiwan & Not stated & Norval et al. (2009) \\
\hline \multirow{2}{*}{ Raillietiella frenatus } & Hawai'i & $8 / 62$ & Goldberg and Bursey (2000) \\
\hline & Hawai'i & $23 / 281$ & Goldberg et al. (2002) \\
\hline \multicolumn{4}{|l|}{ Trematoda } \\
\hline \multirow[t]{3}{*}{ Mesocoelium monas } & Florida & $10 / 100$ & Price and Underwood (1984) \\
\hline & Florida & $2 / 82$ & Sellers and Graham (1987) \\
\hline & Hawai'i & $3 / 62$ & Goldberg and Bursey (2000) \\
\hline \multirow[t]{2}{*}{ Platynosomum fastosum ${ }^{a}$} & Florida & Not stated & Eckerlin and Leigh (1962) \\
\hline & Hawai'i & $2 / 62$ & Goldberg and Bursey (2000) \\
\hline \multirow[t]{4}{*}{ Urotrema scabridum } & Bahamas & $3 / 45$ & Goldberg et al. (1994) \\
\hline & Cuba & $5 / 21$ & Coy Otero (1970) \\
\hline & Florida & $7 / 82$ & Sellers and Graham (1987) \\
\hline & Florida & $4 / 25$ & Goldberg et al. (1994) \\
\hline Urotrema wardi & Cuba & $2 / 21$ & Coy Otero $(1970)$ \\
\hline
\end{tabular}

${ }^{a}$ Larvae.

${ }^{b}$ Nymph. 


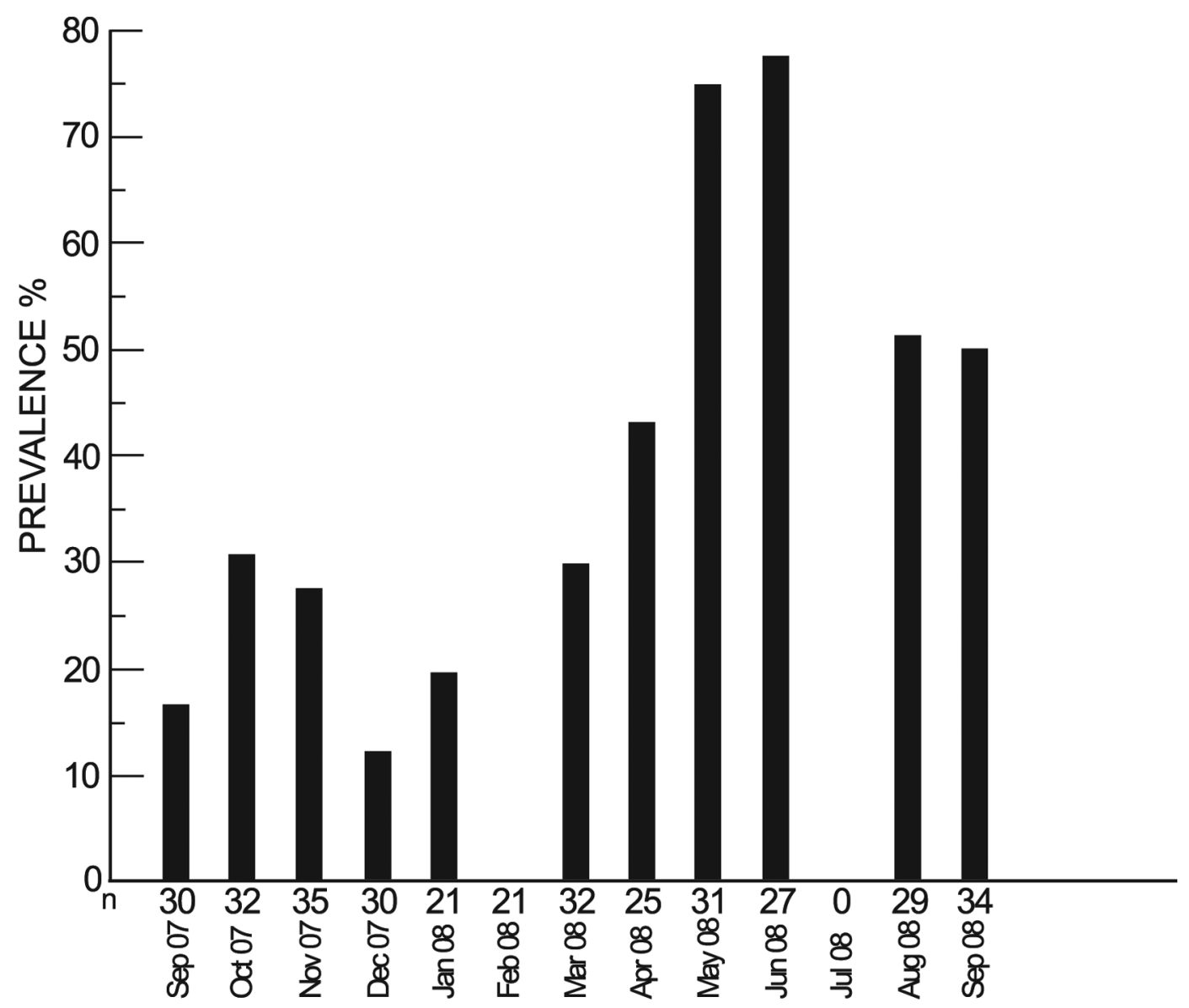

Figure 1. Prevalence by month of Cyrtosomum penneri. Number of hosts examined appears below axis.

acuariid larva; eight anoles had concurrent infections of $C$. penneri and $M$. monas; one anole had a concurrent infection of $C$. penneri and Parapharyngodon sp. Mean number of helminths harbored per infected host was $42 \pm 50$ (1-265).

\section{DISCUSSION}

As noted in Table 2, two species of Cyrtosomum have been reported in $A$. sagrei from Florida: C. penneri by Goldberg et al. (1994) and C. scelopori Gedoelst, 1919, by Price and Underwood (1984). Cyrtosomum penneri can be distinguished from $C$. scelopori by the spicule appearance: the spicules of $C$. scelopori are equal in length (Gedoelst 1919), and those of $C$. penneri are unequal in length (Gambino 1957). We have assigned our specimens to $C$. penneri because the males possess spicules of unequal length. The life cycle of $C$. penneri has not been studied; however, eggs of atractids hatch and larvae develop to third stage in utero; thus, autoinfection is the rule (Anderson 2000). Petter (1966) postulated that in tortoises, at least, atractids are transmitted during copulation. It is of interest to note that in collared lizards, Crotaphytus collaris (Say, 1823), infection rates of $C$. penneri were significantly higher in sexually mature individuals than in juveniles (Pfaffenberger et al. 1986), and in our study the smallest infected male 


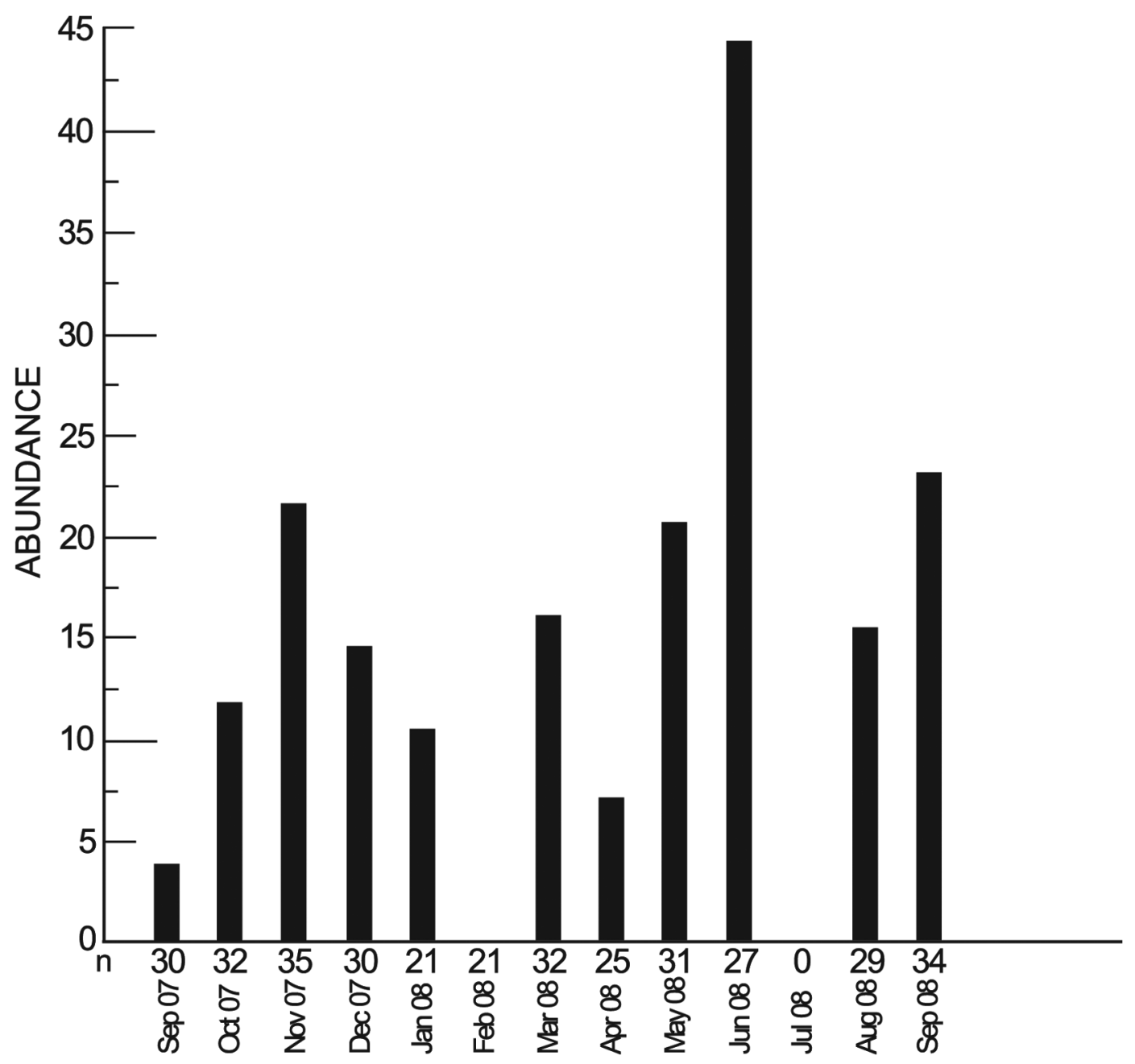

Figure 2. Abundance by month of Cyrtosomum penneri. Number of hosts examined appears below axis.

was $34 \mathrm{~mm}$ SVL (infected individuals, mean $50 \pm 6 \mathrm{~mm}$, range $34-60$ ), and the smallest infected female was $35 \mathrm{~mm}$ SVL (infected individuals, mean $41 \pm 3 \mathrm{~mm}$, range $35-48$ ); all, except the smallest infected male, were within the breeding size range (see Goldberg et al. 2002) and thus supportive of copulation as a possible method for new infections of $C$. penneri. Henderson and Powell (2009) reported a life expectancy of $1.0 \mathrm{yr}$ for $A$. sagrei males and $1.8 \mathrm{yr}$ for females. Thus, maturing uninfected anoles, and seasonal reproduction, could combine to produce conditions that favor low prevalence in winter and high prevalence in summer so that by the end of summer almost all breeding anoles are infected (Figure 1). A similar pattern is seen with abundance (Figure 2). There is lower abundance in winter, and greater abundance in summer; however, abundance of $C$. penneri is indicative of the fecundity of their infrapopulations within $A$. sagrei hosts and the time elapsed since copulation by hosts. Conceivably, the greatest intensity for $C$. penneri could be just before death of the $A$. sagrei host, but without consequence to the host population. 
Baer (1951) suggested that these nematodes, which occur in large numbers and in all stages of development, are possibly living on partially digested matter and should be considered as commensals rather than true parasites.

Mesocoelium monas is a parasite of the intestines of amphibians and reptiles in tropical and subtropical regions (Prudhoe and Bray 1982). Fischthal and Kuntz (1975) reported M. monas (= Mesocoelium sociale Lühe, 1901) from two species of amphibians, Fejervarya limnocharis (Gravenhorst, 1829) and Duttaphrynus melanostictus (Schneider, 1799); a lizard species, fapalura swinhonis Günther, 1864; and a species of snake, Amphiesma stolatum (Linnaeus, 1758), all from Taiwan and very common in the locality where our $A$. sagrei were collected. Price and Underwood (1984) and Sellers and Graham (1987) reported $M$. monas from $A$. sagrei collected in Florida. But it should also be noted that $M$. monas occurs in all biogeographic realms except the Palearctic (Bursey and Goldberg 2003). Thus, no assumption as to whether $M$. monas was transported or acquired can be made. Infection by $M$. monas occurs through ingestion of infected molluscan intermediate hosts or vegetation contaminated with cercarial cysts (Prudhoe and Bray 1982).

There was one female individual of a Parapharyngodon sp. in our sample. To our knowledge, there are no reports of a species of Parapharyngodon in any host from Taiwan, nor are there reports of Parapharyngodon in A. sagrei from Florida. However, there are reports of Parapharyngodon cubensis (Barus and Coy Otero, 1969) in A. sagrei from the Bahamas and Cuba (Barus and Coy Otero 1969, Coy Otero 1970, Coy Otero and Barus 1979, Goldberg et al. 1994). It should be noted that Hasegawa (1988) reported an unidentified species of Parapharyngodon in a lizard, Ateuchosaurus pellopleurus (Hallowell, 1861), collected on Okinawa. Species of Parapharyngodon are identified utilizing characteristics of male individuals; thus identification of our specimen to the species level is not possible.

One larva of a species of acuariid nematode was found. Members of the Acuariidae are usually parasites of the alimentary tract of birds and use a variety of invertebrates as in- termediate hosts, so lizards are considered paratenic/accidental hosts (Anderson 2000).

It is becoming evident that immigrant lizards, under favorable conditions, may transport helminths. Ecological conditions favoring egg survival for monoxenous helminths (direct life cycle, no intermediate host utilized) and appropriate intermediate hosts for heteroxenous helminths (indirect life cycle, obligatory intermediate host) are important considerations in the establishment of immigrant helminth populations. It is evident that the population of $C$. penneri is well established and persistent. But the question becomes, especially for autoinfective helminths, what conditions must be met to spread throughout the host community? More work remains to determine if $C$. penneri can become established in native Taiwanese lizards, as well as if A. sagrei will acquire any of the native parasites.

A study by Kolbe et al. (2004) showed that introduced $A$. sagre $i$ from Hawai' $i$ and Taiwan are considered to have originated from Florida but could not indicate if the introductions were related. The dominant nematodes from the studies in Hawai'i, Cyrtosomum (as Atractis) scelopori and Physaloptera squamatae Harwood, 1932 (Goldberg and Bursey 2000), are absent from lizards in the study reported here, and the dominant nematode from this study, C. penneri, was not recorded in Hawai' $i$, so it seems that the introduction of $A$. sagrei in these two localities were isolated incidents. That the Taiwan population of $A$. sagrei originated in Florida is given additional support by the fact that all three helminths, $C$. penneri, C. scelopori, and P. squamatae, occur in Florida (Table 2).

\section{ACKNOWLEDGMENTS}

We thank Cecilia Nava and Daisy Salguaro (Whittier College) for assistance with dissections.

\section{Literature Cited}

Anderson, R. C. 2000. Nematode parasites of vertebrates: Their development and trans- 
mission. 2nd ed. CABI Publishing, Wallingford, United Kingdom.

Anderson, R. C., A. G. Chabaud, and S. Willmott. 1974. CIH keys to the nematode parasites of vertebrates. No. 1. General introduction. Commonwealth Agricultural Bureaux, Bucks, England.

Baer, K. G. 1951. Ecology of animal parasites. University of Illinois Press, Urbana.

Barus, V., and A. Coy Otero. 1969. Systematic survey of nematodes parasitizing lizards (Sauria) in Cuba. Helminthologia (Bratis.) 10:329-346.

Brower, J. E., J. H. Zar, and C. N. von Ende. 1998. Field and laboratory methods for general ecology. 4th ed. WCB/McGrawHill, Boston, Massachusetts.

Bursey, C. R., and S. R. Goldberg. 2003. Acanthocephalus saurius $\mathrm{n}$ sp. (Acanthocephala: Echinorhynchidae) and other helminths from the lizard Norops limifrons (Sauria: Polychrotidae) from Costa Rica. J. Parasitol. 89:573-576.

Bush, A. O., K. D. Lafferty, J. M. Lotz, and A. W. Shostak. 1997. Parasitology meets ecology on its own terms: Margolis et al. revisited. J. Parasitol. 83:575-583.

Coy Otero, A. 1970. Contribucion al conocimiento de la helmintofauna de los saurios Cubanos. Ciencias (Madr.) 4:1-50.

Coy Otero, A., and V. Barus. 1973. Notes on nematodes of the genus Cyrtosomum (Atractidae) parasitic in Cuban lizards (Sauria). Folia Parasitol. 20:297-305.

- 1979. Nematodes parasitizing Cuban reptiles. Acta Sci. Nat. Acad. Sci. Bohemoslov. Brno 13:1-43.

Eckerlin, R. P., and W. H. Leigh. 1962. Platynosomum fastosum Kossack, 1910 (Trematoda: Dicrocoeliidae) in South Florida. J. Parasitol. 48:49 (supplement).

Fischthal, J. H., and R. E. Kuntz. 1975. Some trematodes of amphibians and reptiles from Taiwan. Proc. Helminthol. Soc. Wash. 42:1-13.

Gambino, J. J. 1957. Cyrtosomum penneri n. sp. (Oxyuroidea; Atractidae). J. Parasitol. 43:76-80.

Gedoelst, L. 1919. Un oxyuridé nouveau parasite d'un reptile. C. R. Seances Soc. Biol. Fil. 82:910-913.
Goldberg, S. R., and C. R. Bursey. 2000. Transport of helminths to Hawaii via the brown anole, Anolis sagrei (Polychrotidae). J. Parasitol. 86:750-755.

Goldberg, S. R., C. R. Bursey, and F. Kraus. 2002. Seasonal variation in the helminth community of the brown anole, Anolis sagrei (Sauria: Polychrotidae), from Oahu, Hawaii. Am. Midl. Nat. 148:409-415.

Goldberg, S. R., C. R. Bursey, and R. Tawil. 1994. Helminth parasites of the bark anole, Anolis distichus, and the brown anole, Anolis sagrei (Polychridae) from Florida and the Bahamas. Caribb. J. Sci. 30:275277.

Hasegawa, H. 1988. Parapharyngodon sp. (Nematoda: Pharyngodonidae) collected from the lizard, Ateuchosaurus pellopleurus (Sauria: Scincidae), on Okinawajimi Island, Japan. Akamata 5:11-14.

Henderson, R. W., and R. Powell. 2009. Natural history of West Indian reptiles. University Press of Florida, Gainesville.

Kolbe, J. J., R. E. Glor, L. R. Schettino, A. C. Lara, A. Larson, and J. B. Losos. 2004. Genetic variation increases during biological invasion by a Cuban lizard. Nature (Lond.) 431:177-181.

Kraus, F. 2009. Alien reptiles and amphibians, a scientific compendium and analysis. Springer, The Netherlands.

Lever, C. 2003. Naturalized reptiles and amphibians of the World. Oxford University Press, Oxford, United Kingdom.

McKeown, S. 1996. A field guide to reptiles and amphibians in the Hawaiian Islands. Diamond Head Publishing, Inc., Los Osos, California.

Norval, G., C. R. Bursey, S. R. Goldberg, C. L. Tung, and J. J. Mao. 2009. Norops sagrei (brown anole) pathology and endoparasite. Herpetol. Bull. 107:42-44.

Norval, G., J. J. Mao, H. P. Chu, and L. C. Chen. 2002. A new record of an introduced species, the brown anole (Anolis sagrei) (Duméril \& Bibron, 1837), in Taiwan. Zool. Stud. 41:332-336.

Petter, A. J. 1966. Équilibre des espèces dans les populations de nématodes parasites du colon des tortues terrestres. Mem. Mus. Natl. Hist. Nat. Paris 39:1-252. 
Pfaffenberger, G. S., T. L. Best, and D. de Bruin. 1986. Helminths of collared lizards (Crotaphytus collaris) from the Pedro Armendariz Lava Field, New Mexico. J. Parasitol. 72:803-806.

Price, W. W., and H. Underwood. 1984. Intestinal helminths of the Cuban anole Anolis sagrei sagrei, from Tampa, Florida. Fla. Sci. 47:205-207.
Prudhoe, S., and R. A. Bray. 1982. Platyhelminth parasites of the Amphibia. Oxford University Press, London.

Sellers, L. G., and G. Graham. 1987. Trematodes of Cuban brown anoles, Anolis sagrei sagrei, from Florida. Proc. Helminthol. Soc. Wash. 54:266-267. 